\title{
Subjetividades de clase, intencionalidad y huelgas ${ }^{1}$
}

\author{
Enrico Mora Malo \\ Universitat Autònoma de Barcelona. Departament de Sociologia \\ 08193 Bellaterra (Barcelona). Spain \\ enrico.mora@uab.es
}

\section{Resumen}

En este artículo presentamos los resultados del análisis del componente intencional de la interacción entre subjetividades colectivas de clase (antagonistas y solidarias) en el contexto de huelga. De entre los diversos procesos que intervienen en la producción de las subjetividades de clase, nos centramos en las huelgas, para subrayar el papel activo que los sujetos mantienen en las relaciones de dominación y explotación clasista. Partimos de una concepción de la subjetividad entendida como fragmentaria y contingente que aplicamos al análisis de clase, y que en este artículo restringimos a los procesos teleológico-estratégicos de las huelgas. Centramos el análisis en un estudio de caso, a través del cual llevamos a cabo un seguimiento de dichos procesos intencionales de las huelgas a lo largo de un período dilatado (desde principios de la década de 1970 hasta finales de la de 1990), protagonizados por los trabajadores y las trabajadoras de una empresa del sector del automoción situada en Cataluña. Los principales dispositivos utilizados para elaborar el material empírico objeto de análisis son: entrevistas en profundidad, consulta de material documental de archivo y recopilación de datos estadísticos. A lo largo del análisis, mostramos las distintas estrategias de las trabajadoras y los trabajadores, así como las de la empresa para el logro de los distintos objetos en disputa en los procesos de huelga. También prestamos atención a los resultados de dichas estrategias y a su significación, y cómo éstas tienen relación con la construcción de subjetividades colectivas de clase. Finalmente, indicamos las tensiones i las confrontaciones que caracterizan a las situaciones tan abiertamente conflictivas como las huelgas, donde se explicitan las relaciones de poder que caracterizan a la producción capitalista patriarcal de la vida.

Palabras clave: clases sociales, discurso, acción racional, conflicto.

1. El presente artículo tiene su origen en una investigación, bajo la forma de tesis doctoral, titulada Las clases sociales como forma de interacción social: Una estrategia de aproximación, dirigida por María Jesús Izquierdo y defendida en la Universitat Autònoma de Barcelona. Esta investigación se ha llevado a cabo en el marco del Grup d'Estudis sobre Sentiments, Emocions i Societat (GESES) de la UAB, cuya coordinadora es M. J. Izquierdo. Específicamente, se ha desarrollado en la línea de investigación Relaciones de producción, subjetividad, sentimientos y acción. Esta línea tiene por objeto analizar la relación entre la creación de la subjetividad y su objetivación. Es decir, se interesa por la relación entre las condiciones que producen subjetividad y las condiciones en las que ésta se expresa y actúa. La noción de relaciones de producción es un concepto clave para abordar este interés, leído en sus dimensiones capitalista y patriarcal. Agradezco a M. J. Izquierdo sus comentarios a lo aquí expuesto, y a $\mathrm{S}$. Melero por su constante apoyo. 


\begin{abstract}
In this article, we show the results of analysis of intentional component of the interaction between collective subjectivities of class (antagonist and of solidarity) in the context of strike. Between the several processes that they take part in the made of subjectivities of class, we consider strikes because we want emphasise the active role that the subjects keep up in the class relationships of the domination and exploitation. We start from a conception of the subjectivity understood as fragmentary and contingent that we apply into analysis of class, but this article we limit to theological and strategic processes of the strikes. We centre the analysis in a case's study, across of which we take a chase of intentional processes of strike from the beginning $70^{\text {th }}$ to the end of $90^{\text {th }}$, they was leaded by the workers of a company of motor's sector, situated in Catalonian. The main devices used to work on empirical material are: interview, consultation archive's documents, and recompilation statistical facts. Throughout the analysis, we show diversity strategies of workers and of the company, for obtaining of distinct objects in dispute in the strike processes. Also, we attend to results of these strategies and their signification and how these take relation with the building of collective subjectivities of class. Finally, we indicate the tensions and confrontations that characterise the conflictive situations of strike where are explicit the relations of power in the capitalist patriarchal production of life.
\end{abstract}

Key words: social classes, discourse, rational action, conflict.

\title{
Sumario
}

1. Introducción $\quad 5$. Los objetos en disputa

2. Referentes teóricos 6. Huelgas y resultados

3. Proceso de producción de datos

7. Conclusiones

4. El componente intencional

Referencias bibliográficas de la interacción de clase.

Aproximación empírica

Anexo

\section{Introducción}

En los debates recientes sobre el análisis de clase, uno de los puntos de especial discusión se refiere al dualismo estructura versus acción. Se trata de una discusión sobre cuál es el elemento que cabe privilegiar o con mayor poder explicativo: la estructura o la acción. No se trata de negar la importancia de lo uno o de lo otro, sino más bien de establecer un orden de prelación. Como decimos en otro lugar (Mora, 2003), se asume que en el análisis de clase no se puede ignorar la acción social y la subjetividad, pero la cuestión fundamental es determinar qué lugar ocupan en dicho análisis. Las disputas son amplias y, en el marco de la tradición marxista, que es en la que nos fijamos, éstas las podemos aglutinar entorno a dos planteamientos con prioridades distintas. El primero prioriza lo que se ha denominado la estructura de clases (algunos ejemplos clásicos son Wright, 1995 [1989], 1994 [1985], 1983 [1978]; Scase, 1992; Miliband, 1990 [1987], 1985; Carchedi, 1975; 
Poulantzas, 1977 [1974], 1978 [1969]). La estructura es el elemento que se debe privilegiar del análisis de clase, y se caracteriza por tener pretensiones objetivistas hasta el punto de poder determinar cuáles son los verdaderos intereses de clase y, por oposición, cuando éstos son erróneos, o sea, cuando se produce la falsa conciencia. El segundo planteamiento prioriza lo que se ha denominado lucha de clases (algunos ejemplos clásicos son Thompson, 1989 [1963], 1984; Przeworski, 1995 [1991], 1988 [1985]; 1987 [1985]; Marglin, 1977), donde las acciones de los sujetos, individuales y colectivos, son vistos desde un horizonte histórico como elementos clave para entender y explicar la estructura de clase.

En el contexto de estas disputas, hemos desarrollado, a lo largo de los últimos años, una propuesta de análisis de clase cuyo propósito es analizar las clases sociales a partir de las relaciones de producción capitalistas patriarcales ${ }^{2}$. Entendemos que la producción de nuestra vida no es sólo capitalista, sino también patriarcal. Ambas se caracterizan por la apropiación del trabajo ajeno (explotación). No se puede explicar la producción de nuestra vida si no se incluye en el análisis la producción doméstica no mercantil en su forma patriarcal. Las relaciones de producción las entendemos como prácticas instituidas e instituyentes en la interacción social de los sujetos. Consideramos que las clases sociales se hacen en los conflictos en la misma medida en que los producen. Las clases sociales son relaciones de dependencia entre subjetividades fragmentarias individuales y colectivas en proceso de formación, que analizamos en el ámbito de las relaciones de producción. Las interacciones van definiendo las relaciones de dependencia en unas circunstancias no escogidas, que operan como contextos disciplinarios que reiteran o socavan los sujetos en la interacción. Estas relaciones se caracterizan por el antagonismo, el conflicto y la lucha, así como por la inestabilidad. Y esto porque los agentes sociales que las protagonizan están dotados de intenciones, deseos y necesidades. Su interacción, en tanto que seres sociales productores de significados, es la interacción discursiva.

Se trata de una amplia propuesta, cuya premisa fundamental es que las clases se forman en la interacción y no previamente, y de la cual aquí vamos a fijarnos en un aspecto específico, el componente intencional de la interacción de clase desde un punto de vista empírico, analizando, a través de un estudio de caso, las estrategias de las trabajadoras y los trabajadores y la dirección de una empresa, los objetos en disputa entre estos actores, y los resultados de las interacciones entre éstos en la situación de huelga ${ }^{3}$.

2. Nuestra propuesta de análisis de clase la construimos a través de una lectura de género del concepto de clase. Consideramos que la noción de clase requiere, en su definición, de los elementos conceptuales que se derivan de una interpretación de la producción de la vida que pone en evidencia la dimensión patriarcal de la misma. Los argumentos y el desarrollo de este punto se puede consultar en Mora (2005).

3. En otro texto (Mora, 2003), ejemplificamos otra dimensión de nuestra propuesta de análisis de clase, fijándonos en la formación de subjetividades fragmentarias de clase en la situación de huelga. 
A continuación, precisamos los referentes teóricos en los que nos apoyamos en este texto, el proceso de producción de datos y el material empírico generado e interpretado a partir de dichos referentes teóricos.

\section{Referentes teóricos}

Como hemos dicho, en este artículo presentamos los resultados del análisis del componente intencional de la interacción entre subjetividades colectivas de clase (antagonistas y solidarias) en el contexto de huelga. De entre los diversos procesos que intervienen en la producción de las subjetividades de clase, nos centramos en las huelgas, para subrayar el papel activo que los sujetos mantienen en las relaciones de dominación y explotación clasista. Partimos de una concepción de la subjetividad entendida como fragmentaria y contingente (Laclau, 1998 [1985]; Laclau y Mouffe, 1987 [1985], 1998 [1996]) que aplicamos al análisis de clase, y que, en este artículo, restringimos a los procesos teleológico-estratégicos de las huelgas.

Por dimensión teleológico-estratégica de la interacción entendemos aquel aspecto de la coordinación de los cursos de acción que es elaborado como un fin deliberado por los sujetos que participan de dichos cursos de acción, eligiendo, en una situación dada, los medios más congruentes y aplicándolos de la forma más adecuada para lograr ese fin con éxito. Desde esta perspectiva, el curso de acción debe constituir el mejor modo de lograr los propósitos de los sujetos, propósitos que deben ser, así mismo, racionales — aspecto teleológico (Habermas, 1987 [1981]; Elster, 2001 [1999], 1997 [1989], 1995 [1979], 1988 [1983]; Bredemieier, 1988 [1978]) $)^{4}$.

4. Sobre la racionalidad de los fines, Elster (1990) plantea que podrían serlo aquéllos que nos conducen a la felicidad. Sin embargo, como el propio Elster pone en evidencia, desear algo que está manifiestamente fuera de nuestro alcance nos puede volver infelices. A veces parece natural decir que tales deseos son irracionales. Una persona de medios moderados a quien obsesiona el deseo de bienes lujosos podría ser considerada irracional. Pero, habitualmente, no diríamos que una persona que vive en un régimen totalitario es irracional si no se libera del deseo de libertad que la vuelve tan desdichada. La adaptación inconsciente a lo inevitable es un mecanismo heterónomo, mientras que los deseos racionales deben ser autónomos, deseos que hay que entenderlos de segundo orden, es decir, elaborados conscientemente. No podemos ser racionales si sólo somos juguete de procesos psíquicos que, sin que lo sepamos, moldean nuestros deseos y valores, sin embargo, habrá que tener en cuenta ese aspecto en cuanto fuga de la racionalidad de la interacción. Esta idea es por lo menos tan fuerte como la intuición de que los deseos racionales son deseos cuya posesión nos hace felices. A veces, las dos ideas apuntan en la misma dirección. Las personas que siempre anhelan lo que no pueden conseguir, no son autónomas ni felices. Las personas que se adaptan al medio por un proceso de planificación consciente, son autónomas y felices (Elster, 1990). Es más, como dice Izquierdo, «hacemos lo que hacemos porque queremos ser felices, porque cuando alcanzamos la felicidad no queremos dejar de serlo, porque cuando no la alcanzamos nos podemos proponer al menos eliminar el sufrimiento. Pero, [...] la felicidad no radica únicamente en la experiencia del bienestar, sino en la consecución del bienestar de aquellos que constituyen nuestro objeto de amor» (Izquierdo, 1998b: 271). 
En el cálculo que los sujetos hacen de su éxito, que nosotros vamos a analizar en la situación de huelga, intervienen las expectativas que tienen de las decisiones de otros sujetos, las trabajadoras y los trabajadores, así como la dirección de la empresa, que también actúan con vistas a la realización de sus propios propósitos, así como las expectativas de los demás sobre sus decisiones y su realización. Las expectativas que tenemos sobre las decisiones de terceros, las expectativas de los demás sobre nuestras decisiones y el despliegue que éstos hacen de sus decisiones son pragmáticas, en la medida en que influyen en la elaboración de nuestros fines y medios, así como en su logro - aspecto estratégico (Elster, 1995 [1979]). Lo que los sujetos definen como fines y como medios para su logro, no se lleva a cabo de forma solipsista, sino en la interacción con los demás, y que en el contexto del conflicto de clase configura los objetos en disputa, como el tiempo, el dinero, el puesto de trabajo o la propia subjetividad de los colectivos implicados. En el curso de la acción, buscamos que el otro quiera algo distinto de lo que quiere, cuando lo que quiere interfiere con lo que queremos nosotros. Hablamos, pues, de las implicaciones que, para los propósitos de uno y su logro, tienen los propósitos y las formas de logro de los demás en situación de conflicto. Si, para cumplir los propósitos de uno, hay que impedir que alguien consiga los suyos, o hay que modificarlos, esto continúa siendo una consecuencia pragmática de tener en cuenta a los demás. Como veremos, buen ejemplo de ello son las distintas estrategias de las trabajadoras y los trabajadores en relación con la dirección de la empresa, y viceversa, en relación con los distintos objetos en disputa, especialmente los que tienen implicaciones sexistas. Desde este punto de vista, podríamos entender, por ejemplo, el sexismo en el mercado de trabajo como un proceso histórico también intencionado. Así, siguiendo el razonamiento de Hartmann (1980 [1976]: 257-8), si la tendencia teórica del capitalismo puro hubiera sido poner a todas las personas que venden su fuerza de trabajo en un plano de igualdad en el mercado, ¿por qué las mujeres aún ocupan una posición inferior a la de los hombres en el mercado de trabajo? Las respuestas posibles son muchas, y buena parte de ellas ignoran el papel de los hombres, como sujetos y agentes, en el mantenimiento de la inferioridad de la mujer en el mercado de trabajo. En particular, los hombres como capitalistas han tenido un papel decisivo en la creación y el mantenimiento de jerarquías dentro del proceso de producción a fin de mantener su poder, lo que consiguieron segmentando el mercado de trabajo (según variables sexuales, étnicas, de edad, etc.) y oponiendo entre sí a los distintos trabajadores y trabajadoras.

Como señala Habermas (1987 [1981]: 125-127), el concepto central de la dimensión teleológico-estratégica es el de una decisión deliberada entre alternativas, encaminada a la realización de un propósito, dirigida por la maximización de utilidad y apoyada en una interpretación de la situación. Los sujetos interpretan el contexto en el cual se hayan inmersos, elaborando puntos de vista, desarrollando intenciones, persiguiendo el propio éxito en relación con los demás y comportándose cooperativamente o conflictivamente en la medida en que ello encaja en sus cálculos. Esta dimensión es racional en cuan- 
to se puede someter a enjuiciamiento por parte de terceros conforme a dos posibles criterios: el criterio de verdad y el criterio de eficacia. Los sujetos pueden hacer afirmaciones verdaderas o falsas, y pueden tener éxito o fracasar, es decir, alcanzar o errar el efecto que se proponen conseguir en el mundo. Y éstas son, en buena medida, las herramientas discursivas habituales en la huelga, especialmente para disputarse la parte de las trabajadoras y los trabajadores indecisas entre secundar la huelga o secundar la dirección de la empresa.

Es difícil separar el aspecto teleológico del estratégico de la interacción social. Habermas usa como criterio para diferenciar dichos aspectos, y convertirlos en tipos de acción, la consideración de si en los cálculos hacemos intervenir la expectativa de otros sujetos o no. Sin embargo, tiene dificultades para concebir una situación en la que la otredad no esté presente, y menos aún la elaboración de expectativas. La diferencia está en el tipo de auditorio que se tiene en cuenta en la elaboración de fines y formas de logro. Consideramos que todo curso de acción siempre se dirige a alguien, aunque sea a uno mismo (entendiéndolo como sí mismo, en el sentido meadiano, y por lo tanto como vínculo permanente de lo social). En este sentido, no habría un monólogo deliberativo teleológico. Siempre se tienen en cuenta, de un modo u otro, a los demás, que la situación de huelga hace especialmente visibles. Así mismo, es evidente que cuando los demás no se reducen a ser sólo una objetivación pasada (en uno mismo, en los fines, en los medios, en los resultados...), sino que, al mismo tiempo, son sujetos con los que chocamos pragmáticamente, la estrategia se torna un elemento mucho más visible. Más si pensamos, como dice Elster (1995 [1979]), que los fines y medios que elaboramos en nuestras interacciones no están dados de una vez para siempre, están sometidos retroactivamente al propio curso de la interacción. Miramos al futuro en su elaboración, deliberando con nosotros mismos y en relación con los demás sobre cuál es la alternativa mejor, en tanto analizamos todos los futuros posibles. En este sentido, la dimensión teleológico-estratégica de la interacción se refiere a un futuro intencional, nuestros fines están orientados al futuro, para el cual movilizamos nuestro presente, y mediante el cual interpretamos nuestro presente en términos del logro de esas intenciones.

\section{Proceso de producción de datos}

Dado nuestro interés en analizar la dimensión teleológico-estratégica de la interacción, era necesario que los datos empíricos se refirieran a situaciones de interacción sostenidas en el tiempo, entre sujetos que se conocieran en algún grado y hubieran interactuado, de forma individual y/o colectiva, en algún momento. Asimismo, la importancia que damos en nuestra propuesta a las relaciones de producción capitalistas patriarcales, implicaba centrarse en una empresa y en familias. La imposibilidad de acceder al ámbito familiar, hizo que el núcleo del estudio de caso fuera una empresa que denominamos MSA para un período de tiempo que va desde principios de la década de 1970 hasta finales de la de 1990. Se trata de una empresa del sector de la industria auxi- 
liar de la automoción situada en Cataluña. La empresa se fundó con capital español, y en sucesivas fases se vendió a diversas transnacionales de capital extranjero. Desde que se originó la empresa como un pequeño taller (finales de la década de 1960), hasta el momento más álgido, se produjo una creciente contratación de trabajadoras y trabajadores. A mediados de los años setenta, llegó a tener casi mil empleados. Pero, a finales de los setenta y, sobre todo, a principios de los ochenta, se consolidó una tendencia de reducción de puestos de trabajo. A finales de los noventa no llegaba a doscientos trabajadores y trabajadoras. La aproximación empírica que hubiéramos preferido habría sido la observación participante. Sin embargo, ese camino estaba fuera de nuestro alcance. Optamos por usar otras técnicas: a) realización de entrevistas biográficas a personas que se conocieran y que hubieran interactuado en algún momento a lo largo del período tomado en consideración, un total de 21 entrevistas; b) realización de entrevistas informativas (a miembros del comité de empresa y de la dirección de la empresa, un total de 3 entrevistas); c) consulta de archivos documentales desde 1965 hasta 2000 (particulares y del Comité de Empresa); d) consulta de datos de plantilla de la empresa. En el anexo, detallamos los perfiles de las personas entrevistadas. La técnica de análisis de los datos cualitativos ha sido el análisis de contenido y del discurso. Para los datos cuantitativos, hemos realizado cálculos de tasas y de tablas bivariadas.

Hemos indicado que ofrecemos un análisis de la dimensión teleológicoestratégica de la interacción clasista, centrándonos en un aspecto específico que caracteriza las relaciones de producción en el capitalismo patriarcal: las huelgas. La importancia que atribuimos al análisis de las huelgas responde al hecho que en los procesos de institucionalización de las relaciones de producción capitalista patriarcales se despliegan estrategias de efectos previstos e imprevistos y, al mismo tiempo, resistencias, para consolidar la extracción del excedente. Fijarnos en las huelgas es fijarse en un elemento visible y explícito de los procesos de producción de las clases sociales. Prestamos especial atención en aquellas interacciones que nos facilita mostrar el carácter socavado de la dimensión instituida de las relaciones de producción capitalista patriarcales: la situación de conflicto laboral que nace del desacuerdo o incluso de la oposición y desemboca en huelgas. Éstas señalan la existencia de unas reglas del juego que son anteriores a los sujetos en interacción, nos ponen en evidencia que la entidad de lo instituido es la reiteración de las acciones, pero al mismo tiempo su fragilidad es la dimensión socavada de lo instituido. El análisis de las huelgas nos permite explicitar el carácter móvil, precario, frágil y al mismo tiempo reiterado y consistente de la elaboración de las subjetividades y estrategias en el contexto de las relaciones de producción, a través del análisis de las propias narraciones de las personas entrevistadas y del material documental (Mora, 2003).

Exponemos un movimiento de un proceso más amplio que lo abarca. Nuestra pretensión no es reducir el análisis de las clases sociales al análisis de las huelgas. Más bien nos gustaría lograr ilustrar el potencial que tiene analizar la producción de clases desde un marco que recupere las interacciones sociales 
de los sujetos en las relaciones de producción capitalista patriarcales y donde la dimensión teleológico-estratégica aquí tratada es un aspecto.

Como ya hemos indicado, tomamos en consideración las huelgas realizadas por las trabajadoras y los trabajadores de MSA desde principios de los años setenta hasta finales de los noventa. En la tabla 1, señalamos las huelgas que las personas entrevistadas destacan de forma especial y que, a lo largo del presente texto, iremos mencionando (como contextos de enunciación) para contextualizar los fragmentos de los discursos seleccionados en la historia de las huelgas llevadas a cabo en esta empresa.

Tabla 1. Huelgas más significativas de las trabajadoras y los trabajadores de MSA

\begin{tabular}{|c|c|c|}
\hline Año & Principales motivos & Tipo \\
\hline 1973 & $\begin{array}{l}\text { Convenio (incremento salarial, reducción jornada laboral, } \\
\text { estabilidad contratación) }\end{array}$ & Indefinida \\
\hline 1974 & Convenio & Paros parciales \\
\hline 1973-1974 & Mejora de las condiciones de trabajo & Paros parciales \\
\hline 1976 & $\begin{array}{l}\text { Solidaridad con las trabajadoras y los trabajadores del Metal } \\
\text { de la comarca } \\
\text { Solidaridad con las organizaciones sindicales y políticas }\end{array}$ & Indefinida \\
\hline 1976 & Mejora de las condiciones educativas y para la libertad de presos & Huelga general \\
\hline 1978 & Convenio (incremento salarial) & Paros parciales \\
\hline 1981 & Apoyo a las instituciones democráticas. Contra el golpe de estado & $\begin{array}{l}\text { Huelga durante } \\
\text { el secuestro de los } \\
\text { parlamentarios y } \\
\text { las parlamentarias }\end{array}$ \\
\hline 1984 & Convenio (incrementos salariales, cuarto de hora del bocadillo) & $\begin{array}{l}\text { Paros parciales } \\
\text { y huelga indefinida }\end{array}$ \\
\hline 1985 & Contra el recorte de pensiones & Huelga general \\
\hline 1986 & $\begin{array}{l}\text { Convenio (incrementos salariales e igualdad salarial entre los hombres } \\
\text { y las mujeres de producción directa) }\end{array}$ & Huelgas indefinidas \\
\hline 1987 & $\begin{array}{l}\text { Convenio (igualdad salarial entre hombres y mujeres, fin del plus } \\
\text { voluntario de remuneración de la empresa) }\end{array}$ & Huelga indefinida \\
\hline 1988 & Contra el plan de empleo juvenil del Gobierno & Huelga general \\
\hline 1989 & Igualdad salarial entre los hombres y las mujeres de producción directa & Huelga indefinida \\
\hline 1992 & Contra la reforma del mercado de trabajo & Huelga general \\
\hline 1994 & $\begin{array}{l}\text { Contra la reforma del mercado de trabajo. Creación de las empresas } \\
\text { de trabajo temporal }\end{array}$ & Huelga general \\
\hline 1997 & $\begin{array}{l}\text { Mantenimiento de los puestos de trabajo. Negociación del plan } \\
\text { de viabilidad de la empresa (primera presentación del expediente de } \\
\text { rescisión de empleo) }\end{array}$ & Huelga indefinida \\
\hline 1997 & $\begin{array}{l}\text { Mantenimiento de los puestos de trabajo. Negociación del plan } \\
\text { de viabilidad de la empresa (segunda presentación del expediente de } \\
\text { rescisión de empleo) }\end{array}$ & $\begin{array}{l}\text { Paros parciales } \\
\text { y huelga indefinida }\end{array}$ \\
\hline
\end{tabular}




\section{El componente intencional de la interacción de clase. Aproximación empírica}

Como hemos señalado en la introducción, la dimensión teleológico-estratégica de la interacción consiste en el aspecto de la coordinación de los cursos de acción que es elaborado como un fin deliberado por los sujetos que participan en dichos cursos de acción, eligiendo, en una situación dada, los medios más congruentes y aplicándolos de la forma más adecuada para lograr ese fin con éxito. En el cálculo que los sujetos hacen de su éxito, intervienen las expectativas que tienen de las decisiones de otros sujetos que también actúan con vistas a la realización de sus propios propósitos, así como las expectativas de los demás sobre sus decisiones y su realización. Las expectativas que tenemos de las decisiones de terceros, las expectativas de los demás sobre nuestras decisiones y el despliegue que éstos hacen de sus decisiones son pragmáticas, en la medida en que influyen en la elaboración de nuestros fines y medios, así como en su logro (aspecto estratégico).

Las personas entrevistadas destacan distintos aspectos de las relaciones que se establecen entre las propias trabajadoras y trabajadores y entre éstos y la dirección de la empresa cuando hay huelga. Las huelgas son un proceso intencional que éstos realizan para lograr sus objetivos ${ }^{5}$. En cuanto proceso intencional colectivo, llevado a cabo por las personas que trabajan en la empresa aglutinados bajo una subjetividad antagonista y solidaria ${ }^{\circ}$, podemos destacar algunos aspectos: las estrategias de las trabajadoras y los trabajadores, las estrategias de la empresa (en particular, las intenciones de la empresa vista por las trabajadoras y los trabajadores que participan de la subjetividad antagonista y la acción de la empresa a través de su política de la envidia), los objetos en disputa y, finalmente, los resultados de las huelgas (en particular, las victorias, las derrotas y los logros).

5. Los objetos en disputa que veremos en el apartado correspondiente están estrechamente ligados con este punto.

6. Las nociones de subjetividad antagonista y de subjetividad solidaria las desarrollamos en Mora (2003). De forma sintética, nos referimos a la formación discursiva (en sentido pragmático) de subjetividades colectivas que se construyen entorno al nosotros y a su relación con el ellos. Antagonista se refiere a cuando la relación entre nosotros y ellos es de confrontación (explícita o implícita). Solidaria, a cuando la relación es de apoyo mutuo. La relación entre subjetividad antagonista y solidaria es muy fuerte: el antagonismo entre las partes puede construir la solidaridad en cada una. Así, en cada nosotros puede haber un ellos diluido por el apoyo mutuo. El ellos se refiere a sujetos tanto de forma directa como indirecta (mediante su substitución por un objeto en disputa). Sostenemos que no hay un nosotros y un ellos fijo y dado una vez por todas. Más bien se trata de un proceso inestable que requiere la constante intervención de los sujetos agentes en su formación, tanto de forma intencional como no intencional. Un ejemplo es la formación de subjetividad antagonista del tipo nosotros los trabajadores contra ellos la empresa y su vicario (la dirección), estableciendose lazos de solidaridad entre ese nosotros que se define en términos antagonistas respecto de aquel ellos. A lo largo de este artículo, indicamos algunas subjetividades de este tipo. 


\subsection{Las estrategias de las trabajadoras y los trabajadores}

Las huelgas son una forma de interacción intencional para lograr múltiples objetivos, como defender los puestos de trabajo, los convenios, los salarios..., para frenar a la empresa en sus intenciones, para poder negociar las contrapartes, para apoyar determinados objetivos políticos...

R: Y bueno, aquí sí que hay bastantes más desde el ochenta y cinco que empezamos lo del expediente de las mujeres, ahí hay cada año huelgas y sobre todo fue en el noventa y siete cuando hubo una huelga muy fuerte por la cuestión salarial, por el convenio, que acabamos aceptando [...] para que la empresa no nos chantajeara para poder renunciar a próximas sentencias y tal.

(RmU. Trabajadora especialista, representante de las trabajadoras y los trabajadores ${ }^{7}$. Enunciado en el contexto de las huelgas contra la discriminación salarial de las mujeres.)

R: Y luego ya de septiembre a octubre, estuvo un mes esta huelga por mejora del convenio para que los sindicatos pudieran negociar.

(RmU. Trabajadora especialista, representante de las trabajadoras y los trabajadores. Enunciado en el contexto de las huelgas por convenio de los años setenta.)

Y esas intenciones se articulan y se planifican en diversas estrategias. Una de las más destacadas por las personas entrevistadas, es sacar el conflicto del contexto de la empresa, haciéndolo público a través de los medios de comunicación, y recabar el apoyo de las organizaciones políticas y sindicales, de las asociaciones vecinales, del poder judicial en forma de sentencias favorables a sus intereses. Esta estrategia es especialmente usada en las grandes huelgas, como la de la lucha contra la discriminación salarial o contra los despidos masivos. Es en estos dos casos cuando se produjeron los problemas más serios de fraccionamiento de los trabajadores entre los que hacían huelga y los que no la hacían. Su presencia en los medios de comunicación fue una dramatización para que los trabajadores se vieran a sí mismos como un colectivo, a través de la imagen que les ofrecían los medios de comunicación. Y las alianzas que se buscaban en el exterior no eran sólo para apoyarles en la lucha, sino también para que les ayudaran en el proceso de construcción o sostenimiento de una subjetividad antagonista del tipo nosotros los trabajadores contra ellos la empresa o bien del tipo nosotras las mujeres trabajadoras que luchamos contra la discriminación salarial.

R: Era que el sacar que la huelga no fuera un tema para ganarla en el terreno económico solo era cuestión de no provocar la situación con los hombres que entraban a trabajar para que la huelga no durara dos días porque allí había un

7. Para cada cita, indicamos el perfil de la persona entrevistada. En el anexo, se puede consultar el listado de perfiles y una breve descripción. 
enfrentamiento en la puerta y la huelga duraba dos días, y si había que ganarla en el terreno político, necesitábamos tiempo para poder hacer todas las batallas políticas, meter a los diputados, meter al parlamento, meter al ministerio, eso no lo consigues en dos días, entonces si tú en la huelga nos ponemos allí con un cordón, hombres y mujeres enfrentados, dos días la policía y se acabó, y necesitabas tiempo para que eso madurara para la opinión pública y las presiones, acompañar a los jueces en que se pronunciaran y eso necesitaba tiempo físico.

(RmU. Trabajadora especialista, representante de las trabajadoras y los trabajadores. Enunciado en el contexto de la huelga contra la discriminación salarial de las mujeres de 1989.)

R: Era el 89, eran las del parlamento de Cataluña, o las de los ayuntamientos, porque utilizábamos los mítines para sacar firmas de los diputados y personalidades especiales como la de Anguita, la de Ribó, muy selectas pero muy concretas, Saracibal, el Redondo. Utilizábamos los mítines para ir a pedir y entonces unas cartas dirigidas a la empresa para que solucionara el problema, esto fue previo a la huelga.

( $\mathrm{RmU}$. Trabajadora especialista, representante de las trabajadoras y los trabajadores. Enunciado en el contexto de la huelga contra la discriminación salarial de las mujeres de 1989.)

R: Allí elaboramos todo un plan de intentar convencer al personal, tanto hombres como mujeres pero sobretodo a las mujeres, de que no era una huelga de un convenio, de que las formas que habíamos utilizado en otros convenios no las podíamos utilizar, de que teníamos que estar llevando el problema a los medios de comunicación, llevarlo fuera del marco de la empresa, podía ser una huelga muy dura, de muchos días, de muchas pérdidas de dinero, pero que no se quedara encerrada en el marco sindical y nosotros teníamos que romper con eso y de allí que nos planteamos desde ir a Madrid a llevar el problema al Ministerio de Trabajo a Asuntos Sociales y al Poder Judicial [...].

(RmU. Trabajadora especialista, representante de las trabajadoras y los trabajadores. Enunciado en el contexto de la huelga contra la discriminación salarial de las mujeres de 1989.)

En las huelgas más habituales, como la de convenio, la estrategia básica persigue, no sólo el paro de la producción, sino también iniciar un proceso que interfiera el desarrollo normal de la organización de la producción y del trabajo en la empresa, buscando incluso provocar fraccionamientos y tensiones entre la dirección y sus delegados,

R: Inclusive tirando mucho, cuando había problemas de material de importación, porque se cerraban las fronteras porque habían huelgas, entonces teníamos que hacer los cálculos a seis meses vista [...].

(RhB. Administrativo, inframasculino. Enunciado en el contexto de las huelgas en general.) 
R: Había los problemas de siempre, de fabricación, de proveedores, de stocks, muchos problemas, entonces cuando llegaba una época mala porque la gente no quería echar horas porque había previsiones de huelgas, no sabías la producción que tenía que salir, había enfrentamientos entre jefes y dirección.

[RhB. Administrativo, inframasculino. Enunciado en el contexto de las huelgas en general.)

Y una huelga implica elaborar una estrategia de lo que es posible ahora y de lo que lo será en el futuro, decidiendo a qué se renuncia y a qué no, definiendo cuál es el orden de lo posible para un momento dado (como en el caso de la huelga para lograr el cuarto de hora de bocadillo, posponiendo para el futuro la eliminación de la discriminación salarial ${ }^{8}$ ).

La intencionalidad de las huelgas, atendiendo a lo que aparece en los discursos de las personas entrevistadas, se concreta en un proceso que entraña la toma de decisiones. Hay huelga porque hay decisiones, y esa decisión de hacer huelga es la decisión de entrar en un proceso de toma de decisiones, porque a la primera decisión seguirán otras, en que cada día, según vayan las cosas, habrá que ir tomando nuevas decisiones. La suerte, entonces, no está echada, hay alternativas, y es uno el que toma el camino, en lugar de seguir un camino ya trazado. Decisiones que hay que renovar cada día mientras dure la huelga,

R: La huelga, normalmente, siempre se va decidiendo de un día para otro. (RhA. Trabajador cualificado, masculino, representante de las trabajadoras y los trabajadores. Enunciado en el contexto de las huelgas en general.)

Se deciden muchas cuestiones, como apoyar a las trabajadoras y a los trabajadores más necesitados para que no se rompa la huelga, o a quien pedir ayuda profesional para oponerse a las intenciones de la empresa, con lo que se conciben fuertes y débiles a la vez, pero en ambos casos agentes. Eso incluye hasta contratar abogados:

R: Se decidió recoger una cantidad de dinero de cada trabajador para crear un fondo que fuera cubriendo las necesidades que íbamos teniendo durante la huelga, y para pagar los gastos de abogaos.

(RhA. Trabajador cualificado, masculino, representante de las trabajadoras y los trabajadores. Enunciado en el contexto de las huelgas contra el expediente de rescisión de empleo de 1997.)

Las personas que hacen huelga delegan en el comité de huelga la forma de organizarla y la persona que la liderará. Quien encabeza la huelga es el comité de huelga, un sujeto colectivo creado con esa única finalidad que puede entrar en conflicto con otro sujeto colectivo, el comité de empresa:

8. En el apartado sobre los objetos en disputa, desarrollamos más este punto. 
R: Entonces, bajo el criterio de que yo no estaba muy de acuerdo en cómo se había hecho, se respetó, quizás se vendió a la gente o la gente lo entendió así de que tenían que ser los propios trabajadores los que llevaran el comité de huelga, porque sabes que el comité de huelga es el que dirige, y ya el comité [de empresa] queda relegado a un segundo término, es el que decide.

(RhG. Trabajador especialista, inframasculino, representante de las trabajadoras y los trabajadores. Enunciado en el contexto de las huelgas contra el expediente de rescisión de empleo de 1997.)

\subsection{Las estrategias de la empresa}

La dimensión teleológica estratégica de la interacción implica un esfuerzo por definir lo que uno quiere y cómo lograrlo, teniendo en cuenta en su elaboración lo que quieren los demás y los medios para lograrlo. Tener en cuenta, en este contexto, hay que tomarlo en un sentido literal. Si, para lograr culminar con éxito los objetivos que una colectividad se ha marcado, debe impedir que otra logre los suyos, o modificar los objetivos del otro, sea por negociación o por manipulación, no deja de ser una consecuencia pragmática de tener en cuenta a los demás. Los sujetos interpretan el contexto en el cual se hallan inmersos, elaborando puntos de vista, desarrollando intenciones, persiguiendo el propio éxito en relación con los demás, y comportándose cooperativamente o conflictivamente en la medida en que ello encaja en sus cálculos. En este marco, la interpretación de las intenciones de la contraparte en las huelgas es fundamental.

\subsubsection{Las intenciones de la empresa vista por las trabajadoras y los trabajadores que participan de alguna subjetividad antagonista}

Para las personas entrevistadas que participan en una subjetividad antagonista, la posición de la dirección de la empresa en relación con las huelgas tiene, evidentemente, un sentido opuesto al que sostienen ellos. Desde el punto de vista intencional, la empresa quiere evitar o romper las huelgas. No hay que olvidar que la diversidad puede obstaculizar la constitución de un sujeto histórico. Crear y potenciar las diferencias es una táctica bien conocida para fraccionar a los colectivos en lucha y para impedir que las necesidades individuales lleguen a ser reconocidas como comunes a otras personas. Tal estrategia evidencia la conciencia que se tiene de los procesos de constitución de las subjetividades colectivas. Para ello, la dirección de la empresa despliega, tanto durante las huelgas, como de forma habitual, políticas que favorezcan la creación de una subjetividad favorable a la empresa o en todo caso impedir el florecimiento de subjetividades antagonistas. Entre las estrategias de división que la empresa lleva a cabo cuando se enfrenta a una huelga, podemos destacar algunas. Fundamentalmente, están dirigidas a producir esquiroles, sobornando, facilitando el acceso a la fábrica, conmoviendo, presionando para que delaten a sus compañeros, juntando a los esquiroles en potencia para fortalecerlos como grupo... Y, en todo ello, poniendo en juego emociones como el miedo, la compasión, la ambición o la vergüenza. 
Los medios para propiciar esa división son variados:

a) Uno consiste en incentivar económicamente a quienes no hacen huelga:

R: Claro, si tu estás en huelga y Pepito y Juanito entran a trabajar, y tú te quedas fuera, y un vez dentro la empresa les dice "sí, pues ahora te voy a dar hasta dinero por trabajar en la huelga», y la empresa pasa el sobre, la gente que va a trabajar en la huelga, un sobre de cinco o diez mil pesetas como premio. Además de su sueldo, eso, para que a ti te fastidies, para mañana si hay otra huelga, no participes, entres a trabajar.

(RhA. Trabajador cualificado, masculino, representante de las trabajadoras y los trabajadores. Enunciado en el contexto de las huelgas en general.)

b) Otro, en fletar autocares para facilitar la entrada de los que no hacían huelga:

R: Total, que ya hubo divisiones ya dentro de esa huelga la empresa fletaba autocares para recoger a la gente en la puerta de su casa y se les metía por los muelles.

(RhG. Trabajador especialista, inframasculino, representante de las trabajadoras y los trabajadores. Enunciado en el contexto de las huelgas contra el expediente de rescisión de empleo de 1997.)

c) En expedientar al comité de empresa, cuando éste se revela conflictivo y efectivo en el liderazgo de una subjetividad antagonista en huelga. Para ello, recurre a medios disciplinarios, presionando a terceros, para que se pueda aplicar la legislación que les permita el despido:

R: A tres compañeras, la empresa fue en todo momento a compañeras que no estaban en la huelga, las presionaba una por una para que ellas fueran a declarar a la policía de que las habíamos amenazado, coaccionado y pegado en la empresa.

(RmU. Trabajadora especialista, representante de las trabajadoras y los trabajadores. Enunciado en el contexto de la huelga contra la discriminación salarial de las mujeres de 1989.)

d) En intentar convencer a una parte de los antagonistas de lo erróneo de los planteamientos de quienes están liderando la huelga. Todo ello para propiciar la división y, con ella, el enfrentamiento entre quienes están en huelga. La empresa tiene la intención de dividirlos y así acabar con la huelga, y sus intenciones pasan por cualquier estrategia para lograrlo:

R: Sí, y la empresa quería romper la huelga llevando a toda la gente que más o menos sabe que puede hacerlo allí, dan una charla y los convence para entrar al día siguiente a trabajar, eso, además esperando que hubiese problemas entre lo que querían y los que no querían entrar, tenían incluso cámaras filmando para que cuando hubiese el mínimo problema, el comité a la calle, y lo tenían todo [...]. Lo que pasa es que alguien avisó al comité que eso iba a ser, y el caso es que nos anticipamos un poco a los acontecimientos yendo a ir a ver al 
alcalde, el alcalde nos dijo «ir a ver al capitán de la guardia civil, que no es el de antes, ha cambiao, es un hombre más dialogante».

(RhS. Trabajador especialista, inframasculino. Enunciado en el contexto de la huelga por convenio, contra la discriminación salarial de las mujeres y el plus voluntario de 1987.)

e) En intentar conmover a quienes están en huelga y, especialmente, a quienes la lideran:

R: En una de las huelgas que estábamos negociando convenio, habíamos convocado unos paro, y nos llamó a este hombre y a mí, a mí como secretario [del comité] y a este hombre porque era el que movía todo el tinglado, nos llamó y dijo: «Si queréis, me pongo de rodillas, pero, por favor, paralizarme la huelga».

(RhA. Trabajador cualificado, masculino, representante de las trabajadoras y los trabajadores. Enunciado en el contexto de las huelgas por convenio de los años setenta.)

f) En colgar la lista con nombres y apellidos de quienes perderían su puesto de trabajo, como, por ejemplo, cuando se produjo el expediente de rescisión de empleo:

R: Bueno, no, mucha gente e incluso muchos trabajadores que todavía estaban con la embriaguez del éxito [de la retirada del expediente de rescisión de empleo] y pensaban que podíamos echarlo atrás [el nuevo expediente que se presentaría unos meses más tarde], y la empresa muy hábilmente llegó un momento en que presentó la lista, la colocó en los tableros, y a partir de ahí se convoca la huelga.

(RhG. Trabajador especialista, inframasculino, representante de las trabajadoras y los trabajadores. Enunciado en el contexto de las huelgas contra el expediente de rescisión de empleo de 1997.)

g) En amenazar, como expresa la propia dirección de empresa, con trasladar la producción a otras plantas, poniendo en evidencia que tener más de una fábrica es una manera de romper la unidad de los trabajadores:

R: ¿’Por qué? Porqué allí no voy a parar, no me hacen huelga, el cliente lo voy a servir.

(RhK. Directivo, masculino. Enunciado en el contexto de las huelgas en general tomado de la conversación entre el directivo de recursos humanos y dos representantes de los trabajadores.)

Y, conjuntamente con esa estrategia de la división, las personas entrevistadas destacan la estrategia de la previsión de stocks (es la caja de resistencia de la empresa, pero es un sacrificio, como la propia caja de resistencia de los trabajadores, porque mantener stocks es caro), para afrontar una huelga dura, 
cuestión que aprendió la dirección de la empresa durante el conflicto del expediente de rescisión de empleo de 1997:

R: Que la empresa tenía que presentar un expediente de regulación de plantilla porque había bajao mucho el trabajo, "pero si está la gente haciendo horas", claro, los que estaban haciendo horas estaban haciendo stock por, si había huelga, poder abastecer al mercao.

(RhN. Trabajador cualificado, inframasculino. Enunciado en el contexto de las huelgas contra el expediente de rescisión de empleo de 1997.)

\subsubsection{La acción de la empresa: plantilla contra clases o la política de la envidia} Pero también cabe resaltar, en este punto, las estrategias cotidianas que la empresa despliega para fomentar la división de las subjetividades antagonistas o poniendo trabas a su constitución por parte de las trabajadoras y los trabajadores. Podemos hablar de una política de la particularización de la subjetividad basada en la envidia que se puede concretar a través de distintas estrategias. La envidia tiene su origen en la experiencia de desigualdad entre equivalentes. Procede de que reciban trato distinto personas que se encuentran en una posición similar, por parte de quienes ocupan una posición de autoridad. La envidia conduce a destruir lo bueno con tal de que no lo disfruten los demás, e impide por ello la alianza entre iguales en un objetivo común, sea contra las jerarquías opresoras o la consecución de bienes mediante el trabajo en cooperación. Pulsar ese sentimiento y regularlo es un recurso básico para impedir que se unan los iguales contra quienes ocupan ilegítimamente posiciones de poder. En la empresa, por ejemplo, esto se hace elaborando complicadas y amplias escalas salariales, y una diversidad microscópica de categorías laborales. Se trata de una producción intencional de subjetividades por parte de la dirección de la empresa. Este tipo de política la podemos ejemplificar a través de la distribución del personal que trabaja en MSA en 1997, antes del expediente de rescisión de empleo, según sexo, categoría profesional, edad y salario base.

Entendemos los datos que vamos a mostrar a continuación como un registro de la acción intencional de la empresa para lograr individualizar la relación con los trabajadores. A tal fin, recurre a la política de la envidia que, según los datos disponibles (1997), intenta obstaculizar el sostenimiento de subjetividades solidarias tratando de forma desigual a los que realizan actividades equivalentes. Podríamos incluso interpretar dicha práctica como el ideal al que la empresa aspiraría en sus relaciones con el personal que tiene contratado: relacionase con ellos de uno en uno. En otro lugar ${ }^{9}$, presentamos los datos en unas tablas de dimensiones muy grandes, porqué lo que interesa es mostrar la práctica de la dirección de la empresa, que es, en términos estadísticos, desagregante. Es por ello que lo preferible no es presentar los datos de un modo agre-

9. Mora (2002), tesis doctoral. Barcelona: Universitat Autònoma de Barcelona. Se puede consultar en Internet: http://www.tdx.cbuc.es/ 
gado. Sería desandar el camino que se ha trazado la empresa hasta casi borrarlo: la estrategia de la división. Sin embargo, el contexto obliga. El formato de un artículo no es el más adecuado para presentar los datos tal y como la empresa ha dejado su rastro desagregante. Contradiciéndonos a nosotros mismos, presentamos solamente unas tablas resumen en las que mostramos una tasa mediante la cual se puede sintetizar la intensidad de la desagregación que lleva a cabo la empresa, pero agregando la pluralidad de categorías que emplea la dirección de la empresa y las edades. Esa tasa la llamamos tasa de fragmentación de la estrategia divide y vencerás.

Según los datos disponibles, la fragmentación de la plantilla es muy grande, si tomamos como indicador de la fragmentación a la política salarial. La presentaremos a continuación en relación con el sexo - tabla 2-, con la categoría profesional — tabla 3- y con la edad — tabla 4- (en la tabla 5, resumimos la composición de la plantilla según sexo, edad, grupos de categoría profesional y masa salarial).

La fragmentación es más intensa entre hombres que entre mujeres (por cada hombre con una categoría salarial diferente, hay casi cuatro mujeres). Esto es lógico si pensamos que la estructura de la plantilla concentra a las mujeres sobre todo en las categorías laborales vinculadas con la producción en planta o la administración, mientras que los hombres tienen presencia en todas las categorías. De todos modos, podría indicar también que la empresa teme más a los hombres que a las mujeres, si tenemos en cuenta que son dos grupos de casi el mismo tamaño, o que no puede asumir el coste que representaría fragmentar a las mujeres. A medida que la categoría profesional aumenta en cualificación y jerarquía, aumenta la fragmentación. El límite superior de la fragmentación es que haya un nivel salarial distinto para cada trabajador con una misma categoría profesional, un nivel intermedio sería una escala salarial según la categoría acompañada de pequeñas diferencias internas (ejemplificaría la

Tabla 2. Tasa de fragmentación de trabajadoras y trabajadores de MSA según salario base (mensual) y sexo (1997)

\begin{tabular}{lccc}
\hline & \multicolumn{2}{c}{ Sexo } & \\
\cline { 2 - 3 } & Hombres & Mujeres & Total general \\
\hline No de trabajadoras y trabajadores & 195 & 228 & 423 \\
\hline No de categorías & 164 & 55 & 214 \\
\hline $\begin{array}{l}\text { Tasa de fragmentación de trabajadoras } \\
\text { y trabajadores según categoría }\end{array}$ & $1,19^{*}$ & 4,15 & 1,98 \\
$\begin{array}{l}\text { \% de trabajadoras y trabajadores } \\
\text { sobre total plantilla }\end{array}$ & $46,1 \%$ & $53,9 \%$ & $100 \%$ \\
\hline \% Categorías sobre total categorías & $76,6 \%$ & $25,7 \%$ & $100 \%$ \\
\hline
\end{tabular}

* = Por cada 1,19 trabajadores, hay una categoría salarial

Fuente: Material de archivo. Elaboración propia. 
aspiración de individualizar la relación entre empresa y empleado dificultando la creación de subjetividades solidarias). En el único caso en que la fragmentación disminuye un poco, es entre el personal especialista y administrativo. Si nos fijamos en la edad, los más jóvenes y los más viejos son los más fragmentados, al aproximarse al ideal de individualización máxima. Eso no excluye que el grupo de adultos (que aglutina a buena parte de la plantilla) no esté fuertemente fragmentado.

Tabla 3. Tasa de fragmentación de trabajadoras y trabajadores de MSA según salario base (mensual) y categoría profesional agrupada (1997)

\begin{tabular}{|c|c|c|c|c|c|c|c|c|}
\hline & \multicolumn{8}{|c|}{ Categorías profesionales agrupadas } \\
\hline & $\begin{array}{l}\text { Personal } \\
\text { especialista }\end{array}$ & $\begin{array}{l}\text { Personal } \\
\text { cualificado }\end{array}$ & $\begin{array}{l}\text { Personal } \\
\text { administrativo }\end{array}$ & $\begin{array}{l}\text { Personal } \\
\text { técnico }\end{array}$ & $\begin{array}{l}\text { Jefes } \\
\text { inferiores }\end{array}$ & $\begin{array}{l}\text { Jefes } \\
\text { intermedios }\end{array}$ & $\begin{array}{l}\text { Jefes } \\
\text { superiores }\end{array}$ & $\begin{array}{l}\text { Total } \\
\text { general }\end{array}$ \\
\hline $\begin{array}{l}\text { No de trabajadoras } \\
\text { y trabajadores }\end{array}$ & 249 & 83 & 21 & 35 & 11 & 6 & 18 & 423 \\
\hline No de categorías & 69 & 70 & 12 & 33 & 11 & 6 & 15 & 214 \\
\hline $\begin{array}{l}\text { Tasa de fragmentación } \\
\text { de trabajadoras } \\
\text { y trabajadores } \\
\text { según categoría }\end{array}$ & 3,61 & 1,19 & 1,75 & 1,06 & 1,00 & 1,00 & 1,20 & 1,98 \\
\hline $\begin{array}{l}\text { \% de trabajadoras } \\
\text { y trabajadores sobre } \\
\text { total plantilla }\end{array}$ & $58,9 \%$ & $19,6 \%$ & $5,0 \%$ & $8,3 \%$ & $2,6 \%$ & $1,4 \%$ & $4,3 \%$ & $100 \%$ \\
\hline $\begin{array}{l}\text { \% de categorías sobre } \\
\text { total categorías }\end{array}$ & $32,2 \%$ & $32,7 \%$ & $5,6 \%$ & $15,4 \%$ & $5,1 \%$ & $2,8 \%$ & $7,0 \%$ & $100 \%$ \\
\hline
\end{tabular}

Fuente: Material de archivo. Elaboración propia.

Tabla 4. Tasa de fragmentación de trabajadoras y trabajadores de MSA según salario base (mensual) y edad agrupada (1997)

\begin{tabular}{|c|c|c|c|c|}
\hline & \multicolumn{3}{|c|}{ Grupos de edad } & \multirow[b]{2}{*}{ Total general } \\
\hline & $24-35$ & $36-49$ & $50-63$ & \\
\hline $\begin{array}{l}\text { No de trabajadoras } \\
\text { y trabajadores }\end{array}$ & 43 & 301 & 79 & 423 \\
\hline No de categorías & 30 & 134 & 72 & 214 \\
\hline $\begin{array}{l}\text { Tasa de fragmentación de trabajadoras } \\
\text { y trabajadores según categoría }\end{array}$ & 1,43 & 2,25 & 1,10 & 1,98 \\
\hline $\begin{array}{l}\% \text { de trabajadoras y trabajadores } \\
\text { sobre total plantilla }\end{array}$ & $10,2 \%$ & $71,2 \%$ & $18,7 \%$ & $100 \%$ \\
\hline$\%$ de categorías sobre total categorías & $14,0 \%$ & $62,6 \%$ & $33,6 \%$ & $100 \%$ \\
\hline
\end{tabular}

Fuente: Material de archivo. Elaboración propia. 
Tabla 5. Plantilla de MSA según grupos de edad, sexo, grupos de categoría profesional y masa salarial (1997)

\begin{tabular}{|c|c|c|c|c|c|c|c|c|c|c|c|c|c|c|c|}
\hline \multirow{2}{*}{$\begin{array}{l}\text { Grupos } \\
\text { de edad } \\
\end{array}$} & & \multicolumn{5}{|l|}{ Mujeres } & \multicolumn{8}{|l|}{ Hombres } & \multirow[b]{2}{*}{ Total } \\
\hline & & Especialistas & \multirow{2}{*}{$\frac{\text { Administrativas }}{7,0}$} & \multirow{2}{*}{$\begin{array}{c}\text { Técnicas } \\
2,3\end{array}$} & \multirow{2}{*}{$\begin{array}{c}\begin{array}{l}\text { Jefas } \\
\text { superiores }\end{array} \\
0,0\end{array}$} & \multirow{2}{*}{$\begin{array}{c}\begin{array}{l}\text { Total } \\
\text { mujeres }\end{array} \\
25,6\end{array}$} & \multirow{2}{*}{$\begin{array}{c}\text { Especialistas } \\
41,9\end{array}$} & \multirow{2}{*}{$\begin{array}{c}\text { Cualificados } \\
14,0\end{array}$} & \multirow{2}{*}{$\frac{\text { Administrativos }}{7,0}$} & \multirow{2}{*}{$\begin{array}{c}\text { Técnicos } \\
7,0\end{array}$} & \multirow{2}{*}{$\begin{array}{l}\begin{array}{l}\text { Jefes } \\
\text { inferiores }\end{array} \\
4,7\end{array}$} & \multirow{2}{*}{$\begin{array}{l}\begin{array}{l}\text { Jefes } \\
\text { intermedios }\end{array} \\
0,0\end{array}$} & \multirow{2}{*}{$\begin{array}{l}\text { Jefes } \\
\text { superiores } \\
0,0\end{array}$} & \multirow{2}{*}{\begin{tabular}{|c|}
$\begin{array}{c}\text { Total } \\
\text { hombres }\end{array}$ \\
74,4
\end{tabular}} & \\
\hline $24-35$ & $\% \mathrm{f}$ & 16,3 & & & & & & & & & & & & & 100 \\
\hline & $\%$ c & 3,3 & 21,4 & 33,3 & 0,0 & 4,8 & 46,2 & 7,2 & 42,9 & 9,4 & 18,2 & 0,0 & 0,0 & 16,4 & 10,2 \\
\hline & $\% \mathrm{t}$ & 1,7 & 0,7 & 0,2 & 0,0 & 2,6 & 4,3 & 1,4 & 0,7 & 0,7 & 0,5 & 0,0 & 0,0 & 7,6 & 10,2 \\
\hline & $\% \mathrm{t} \$$ & 1,4 & 0,7 & 0,3 & 0,0 & 2,3 & 3,5 & 1,3 & 0,7 & 1,0 & 0,7 & 0,0 & 0,0 & 7,2 & 9,5 \\
\hline $36-49$ & $\% \mathrm{f}$ & 63,1 & 3,7 & 0,7 & 0,3 & 67,8 & 4,0 & 15,3 & 1,3 & 5,3 & 2,0 & 1,3 & 3,0 & 32,2 & 100 \\
\hline & $\%$ c & 90,5 & 78,6 & 66,7 & 100 & 89,5 & 30,8 & 55,4 & 57,1 & 50,0 & 54,5 & 66,7 & 52,9 & 49,7 & 71,2 \\
\hline & $\% \mathrm{t}$ & 44,9 & 2,6 & 0,5 & 0,2 & 48,2 & 2,8 & 10,9 & 0,9 & 3,8 & 1,4 & 0,9 & 2,1 & 22,9 & 71,2 \\
\hline & $\% \mathrm{t} \$$ & 38,0 & 2,5 & 0,6 & 0,3 & 41,4 & 2,4 & 10,6 & 1,1 & 5,3 & 1,9 & 1,4 & 4,7 & 27,5 & 68,9 \\
\hline $50-63$ & $\% \mathrm{f}$ & 16,5 & 0,0 & 0,0 & 0,0 & 16,5 & 11,4 & 39,2 & 0,0 & 16,5 & 3,8 & 2,5 & 10,1 & 83,5 & 100 \\
\hline & $\% \mathrm{c}$ & 6,2 & 0,0 & 0,0 & 0,0 & 5,7 & 23,1 & 37,3 & 0,0 & 40,6 & 27,3 & 33,3 & 47,1 & 33,8 & 18,7 \\
\hline & $\% \mathrm{t}$ & 3,1 & 0,0 & 0,0 & 0,0 & 3,1 & 2,1 & 7,3 & 0,0 & 3,1 & 0,7 & 0,5 & 1,9 & 15,6 & 18,7 \\
\hline & $\%$ t\$ & 2,7 & 0,0 & 0,0 & 0,0 & 2,7 & 1,8 & 7,2 & 0,0 & 4,4 & 0,9 & 0,8 & 3,8 & 18,9 & 21,5 \\
\hline Total & $\% \mathrm{f}$ & 49,6 & 3,3 & 0,7 & 0,2 & 53,9 & 9,2 & 19,6 & 1,7 & 7,6 & 2,6 & 1,4 & 4,0 & 46,1 & 100 \\
\hline & $\%$ c & 100 & 100 & 100 & 100 & 100 & 100 & 100 & 100 & 100 & 100 & 100 & 100 & 100 & 100 \\
\hline & $\% \mathrm{t}$ & 49,6 & 3,3 & 0,7 & 0,2 & 53,9 & 9,2 & 19,6 & 1,7 & 7,6 & 2,6 & 1,4 & 4,0 & 46,1 & 100 \\
\hline & $\% \mathrm{t} \$$ & 42,0 & 3,2 & 0,9 & 0,3 & 46,4 & 7,8 & 19,1 & 1,8 & 10,7 & 3,5 & 2,2 & 8,5 & 53,6 & 100 \\
\hline
\end{tabular}

$\% \mathrm{f}=\%$ sobre el total de la fila; $\% \mathrm{c}=\%$ sobre el total de la columna; $\% \mathrm{t}=\%$ sobre el total de la tabla; $\% \mathrm{t} \$=\%$ sobre el total de la masa salarial.

Fuente: Material de archivo. Elaboración propia. 


\section{Los objetos en disputa}

El momento innovador ante la dinámica cotidiana pasa, más que por el yo, por el nosotros. Si aceptamos que nos vamos produciendo como sujetos en las relaciones que establecemos con los demás, es razonable pensar que también a través de las relaciones con los demás nos innovamos, planteando alternativas a nuestra manera de vivir, sean éstas conservadoras o transformadoras. La construcción de los intereses pasa también por el momento nosotros. Según como construyamos ese nosotros, podremos establecer distintos intereses. Los de clase se refieren a nuestra participación en las relaciones de producción. La elaboración colectiva de los intereses en términos de un nosotros clase implica priorizar, dado que los intereses sometidos a elaboración como nosotros clase se refieren únicamente a las relaciones de producción, mientras que no son los únicos que manejamos en nuestra vida como sujetos individuales. Como vamos a ver, para el caso de las huelgas analizadas, la prioridad de los objetos en disputa irá oscilando entre intereses más propios del capitalismo que del patriarcado e intereses más propios del patriarcado que del capitalismo, donde los segundos, a excepción de la huelga de 1989 contra la discriminación salarial, quedan subordinados a los primeros.

Una huelga se lleva a cabo como un proceso para afrontar determinadas cuestiones que son problemáticas para los que la promueven y para aquéllos a los que se amenaza con la misma. Se requiere construir el problema de tal modo que permita establecer una subjetividad antagonista. Inversamente, evitar la huelga requiere construir una subjetividad solidaria con la empresa. Y estas cuestiones problemáticas tienen que elaborarse conjuntamente, de tal modo que legitimen la movilización y la huelga ${ }^{10}$.

La huelga es, en sí misma, un objeto en disputa, quizás el primer objeto en disputa. Y lo es a un doble nivel. Un objeto en disputa entre las propias trabajadoras y trabajadores y entre aquéllos que comparten una subjetividad antagonista y la empresa.

Cada huelga requiere la elaboración de su necesidad por parte de las trabajadoras y los trabajadores como colectivo. La primera disputa a resolver es, pues, resolver la disputa por el trabajo: unos quieren trabajar y los otros no quieren trabajar como modo de lograr unos determinados objetivos. Ese proceso, que intenta influir por todos los medios en la empresa (como hemos visto a través de sus estrategias de división, especialmente fomentando los esquiroles), concluye cuando se logra formar, por enésima vez, una renovada subjetividad antagonista que considera la huelga, para esas circunstancias, como el único poder que las personas que trabajan en la empresa tienen frente a ella. Lo

10. Esto no siempre es fácil. Un ejemplo especialmente claro son las huelgas contra los despidos masivos de 1997, donde se producen, en el segundo intento de la empresa de reducir la plantilla, dos posibles objetos de disputa: los que están a favor de luchar por los empleos y lo que están a favor de negociar las indemnizaciones mayores posibles. En asamblea, se optará por la primera opción, pero aún sigue abierta la discusión. 
único que pueden hacer es dejar de trabajar (aunque podrían hacer otras cosas, como huelgas de celo):

R: No aceptamos eso, se lo propusimos a los trabajadores, y todo el mundo de acuerdo en que no aceptamos eso, y se hace huelga para paralizar eso.

(RhA. Trabajador cualificado, masculino, representante de las trabajadoras y los trabajadores. Enunciado en el contexto de las huelgas contra el expediente de rescisión de empleo de 1997.)

Este proceso, si bien es siempre original para cada circunstancia, forma parte de una trayectoria histórica de unas trabajadoras y unos trabajadores que, de algún modo, ven la huelga como algo normal en la vida laboral. Como algo instituido. La huelga como expresión máxima de la confrontación entre las contrapartes tiene un arraigo especial en la construcción colectiva que las personas entrevistadas que participan de una subjetividad antagonista hacen de la noción de trabajo. Los discursos de las personas entrevistadas nos permiten destacar que entrar en el mundo del trabajo capitalista es entrar en contacto con las huelgas:

R: Cuando llegué a trabajar y llevaba cuatro días como aquél que dice, y empecé a ver esos follones, esas manifestaciones, esos paros, esas huelgas, yo decía: "¿Qué pasa aquí?».

(RhA. Trabajador cualificado, masculino, representante de las trabajadoras y los trabajadores. Enunciado en el contexto de las huelgas por convenio de 1973.)

Se descubre que en esta empresa se viene a trabajar de un modo distinto a como lo hacen en otras empresas. Trabajar implica luchar. Para buena parte del período estudiado, el concepto de trabajo que construyen las personas entrevistadas que participan de una subjetividad antagonista es un concepto no sólo estrictamente laboral, sino también político (en el sentido de incidir en la política de la empresa, con todos los medios disponibles, lo que incluye, obviamente, la huelga), hasta el punto que, cuando se deja de luchar, esto deviene algo anómalo (aunque suponga evitar los sacrificios que toda huelga implica para las trabajadoras y los trabajadores que la realizan):

R: Ahora no, por las circunstancias del trabajo y del mercado, por todo, ahora es muy diferente, pero ahí en esa empresa cuando yo empecé a trabajar en el setenta y dos, me parece que los cinco, siete o diez años primeros, era cada año una huelga.

(RhI. Team leader, masculino. Enunciado en el contexto de las huelgas en general.)

Es una concepción que instituye la huelga como una práctica habitual. La huelga, como hemos indicado más arriba, es también un objeto en disputa entre las personas que comparten una subjetividad antagonista y la empre- 
sa. El conflicto en MSA es constante desde el tardofranquismo hasta el expediente de 1997, lo que impide la paz social tan anhelada por parte de la dirección de la empresa. La paz social en la empresa es quizás uno de los más importantes objetos en disputa que expresa la dirección de la empresa y que constituye para ella el reverso de la huelga:

R: ¿Convenio? Un momento, como decía antes hL: «Aquí tienes la plataforma y ya tienes quince días de huelga».

(RhK. Directivo, masculino. Enunciado en el contexto de las huelgas en general.)

Y lograr la paz social se convierte en un objetivo fundamental en el contexto de una empresa con huelgas para cada negociación:

R: Si bien es verdad que bueno, también por mi parte tendría que decirte que uno y otros, entre dirección y comité, no los sindicatos, porque han querido entrar y a veces no se les ha dejao, nunca se ha llegao a un acuerdo, cuando había un convenio pues en principio hay que hacer huelga, no existía diálogo, y hoy existe, últimamente se han firmao dos convenios por cuatro años, firmados por mí, después del expediente del noventa y siete se firmó uno por cuatro años, del noventa y siete al dos mil, y el último del dos mil uno al dos mil cuatro, con lo cual lo que he pretendido siempre dar es tranquilidad.

(RhK. Directivo, masculino. Enunciado en el contexto de las huelgas en general extraído de la conversación.)

Las huelgas como práctica habitual incorporan un elemento más en la negociación. La capacidad de influir en la negociación de las condiciones para que se restablezca la paz social y, por lo tanto, convertirla en un objeto más de disputa. La paz social tiene un precio, y por ella hay que pagar cada vez. No está dada por descontado. De ahí, posiblemente, que para la dirección le parezca tan aberrante la estrategia de la huelga habitual, de la huelga como institución,

R: Es una aberración el plantear una huelga antes de un convenio, pero si la empresa no ha dicho nada, el comité no ha dicho nada.

(RhK. Directivo, masculino. Enunciado en el contexto de las huelgas en general, extraído de la conversación entre los representantes sindicales y el director de recursos humanos.)

Una aberración para la dirección porque se negocia la paz social, no se da por descontado, no se naturaliza.

El hecho de que el empresario dependa, para lograr sus propósitos, del trabajo de los asalariados, se pone en evidencia precisamente en la huelga. Y ése es el fondo de cualquier conflicto antagonista. El interés por el trabajo abstracto, en cuanto productor de plusvalía, por parte de la empresa, la obliga a 
negociar cuestiones concretas del mismo (los salarios, los tiempos, los convenios...).

Pero la otra cara de la misma moneda es que esa dependencia del trabajo abstracto es precisamente de trabajo abstracto, lo que quiere decir que se puede encontrar en cualquier otro lugar de la organización económica capitalista, porque el trabajo abstracto se ha convertido en trabajo general, no diferenciado, lo que facilita la substitución de un trabajador por otro. La amenaza de cierre patronal, de cierre de la empresa es el otro extremo:

R: Si esto continúa igual, y no tenemos follón no tenemos conflictos, y la gente se continúa ganando la vida, aquí el trabajo llega, pero si empezamos mañana: "No sé qué, huelga y calle», al final alguien dice [silba]: «Esto que tengo aquí, me lo llevo pa allá».

(RhK. Directivo, masculino. Enunciado en el contexto de las huelgas en general.)

Y junto a ello, la amenaza de despidos masivos.

El despido disciplinario es uno de esos objetos en disputa habitual en muchas huelgas, sobre todo como efecto de las represalias de la empresa contra quienes activan la generación de subjetividades antagonistas en huelga:

R: Es decir, una huelga los despidió y por otra huelga conseguimos que entraran.

(RhA. Trabajador cualificado, masculino, representante de las trabajadoras y los trabajadores. Enunciado en el contexto de las huelgas por convenio y políticas de los años setenta.)

El despido masivo se convertirá en objeto de disputa cuando la empresa presenta el expediente de rescisión de empleo en 1997:

R: Esta huelga que tuvimos cuando lo del expediente de los ciento cincuenta y nueve despedidos [...].

(RhA. Trabajador cualificado, masculino, representante de las trabajadoras y los trabajadores. Enunciado en el contexto de las huelgas contra el expediente de rescisión de empleo de 1997.)

Si el despido es, para las personas contratadas, el objeto en disputa concreto más importante (no hay que olvidar que del empleo depende el acceso a los medios de vida para aquéllos que, en el capitalismo, no disponen de medios de producción), no quiere decir que no se hayan producido numerosas huelgas por otros objetos. En especial, los salarios, los tiempos y los convenios.

El salario es una forma clásica de objeto en disputa en las relaciones entre la dirección de la empresa y las trabajadoras y los trabajadores. Serán habituales las disputas en torno al aumento de primas: 
R: Aquí no, aquí cuando llegué hubo una huelga muy grande por un aumento de quinientas pesetas a la semana, que entonces era mucho, porque se estaban cobrando mil ochocientas a la semana [...] Entonces fue cuando la empresa se emperró en que no y los trabajadores en que sí [...].

(RhS. Trabajador especialista, inframasculino. Enunciado en el contexto de las huelgas por convenio de 1973.)

R: Una huelga reivindicando siempre salario, y después otras cosas, pero casi siempre el salario.

(RhI. Team leader, masculino. Enunciado en el contexto de las huelgas en general.)

R: Planteemos una huelga en base a [...] «Es que quiero un diez por ciento». Muy bien, depende como me pilles con los clientes te lo doy, y el año que viene te digo: «No, el diez no, ahora te cierro las puertas [pausa con tres chasquidos de dedos] y te vas», el diez te lo daba antes y ahora ni un puto duro.

(RhK. Directivo, masculino. Enunciado en el contexto de las huelgas en general, tomado del contexto de la conversación.)

Pero, en torno a los salarios, también hubo un objeto en disputa que hizo historia. La discriminación salarial de las mujeres de producción directa dio lugar a una lucha cuyo contenido no sólo fue económico, sino también simbólico:

R: Nosotros hemos tenido muchas reuniones de convenio que han sido muy fuertes, pero todo lo gordo que ha sido fuerte en esos convenios, en esas huelgas de convenio, siempre venía a relucir el problema de las mujeres, porque yo una de las que viví muy fuertes que fue años anteriores a ésa, que iban a por la mujeres, iban a por nosotras, iban a por las mujeres del comité de empresa, la empresa iba a hacer una jugada allí que iban a por nosotras.

$(\mathrm{RmR}$. Trabajadora especialista, infrafemenina. Enunciado en el contexto de las huelgas contra la discriminación salarial de las mujeres, en general, y por convenio en general.)

El tiempo también es otro objeto en disputa clásico para las trabajadoras y los trabajadores de MSA. Se lucha por el tiempo y en el tiempo. En efecto, toda huelga tiene una dimensión temporal, el resultado de la misma está asociado a la cantidad de días que se es capaz de resistir:

R: Cuando acabó todo eso, porque estuvimos quince días o un mes de huelga $[\ldots]$ yo es que en fechas y en tiempo me pierdo mucho, no me acuerdo.

(RhI. Team leader, masculino. Enunciado en el contexto de las huelgas por convenio y políticas de los años setenta.) 
Pero no todas las huelgas implican resistencia, ya que la duración de las mismas es muy variable:

R: A lo mejor han parao, ahora ha parao un día por alguna cosa que haya pasao, pero antes de los despidos, cualquier problema que había y si la empresa no hacía caso y no se resolvía [...] hacían un día de huelga, o media jornada, o paraban dos horas hoy y dos pasado mañana y así [...], al final se conseguía, pero ese esfuerzo ya no [...] y más como están las cosas, ese esfuerzo ya no [...] cada vez que la empresa dice algo, el comité lo pone a votación y siempre sale que sí, aunque sea por poca diferencia pero siempre sale que sí.

( RhN. Trabajador cualificado, inframasculino. Enunciado en el contexto de las huelgas en general.)

La determinación de lo que tendrá que durar la huelga es importante para su sostenimiento:

R: Ahora, tenían que ser honraos también, porque si se quedaba de hacer dos horas de paro, son dos horas, ahora, que me diga «es que es una huelga indefinida», entiendo que puede ser de tres días a veinte días, una vez tuvimos veinte o veinticinco, y claro, un paro así a una persona que depende solamente de sus ingresos y los problemas que tiene en su casa, pues yo lo reconozco, pero también hay que ser humano y cuando llega el momento de hacer una presión por dos o tres horas, tampoco se va a morir la gente.

(RhB. Administrativo, inframasculino. Enunciado en el contexto de las huelgas por convenio y políticas de los años setenta.)

Asimismo, como decíamos, el tiempo es también objeto de disputa. Disputa entorno a los tiempos de descanso para los productores de planta, que históricamente logran instaurar el cuarto de hora de bocadillo. Pero se trata de una lucha donde lo que está en disputa no es propiamente el tiempo, el cuarto de hora de bocadillo. Lo que se negocia se hace en términos de tiempo, pero sigue siendo tiempo en la empresa, tiempo libre en la empresa y no tiempo liberado de estar presente en la empresa. Lo que está en juego es la posibilidad de ganar un espacio de relación para las trabajadoras y los trabajadores. Se puede hacer una lectura política del cuarto de hora de bocadillo. El cuarto de hora del bocadillo es la posibilidad de relacionarse, de coordinarse, de establecer vínculos de amistad. Comer tiene una enorme fuerza imaginaria, es incorporar, tiene que ver directamente con el amor, la aceptación, el reconocimiento. Uno se come lo que quiere y quiere tener un espacio para comer. Comer es el fundamento de la socialización, uno come las características de las personas que ama, come con la mirada y de este modo se socializa, cuando no puede tener a quien ama (no puede incorporar al objeto de amor) se come, se incorporan sus cualidades. Tener un tiempo para comer en el marco laboral, es incorporar en la empresa el cuidado, no aceptar la disociación entre trabajador y persona. La 
importancia del cuarto de hora la podemos valorar si pensamos que, a cambio de su logro, las trabajadoras y los trabajadores retiraron de la negociación el tema de la discriminación salarial de las mujeres, en un momento en que el comité que negociaba estaba formado precisamente por las mujeres que habían iniciado la reivindicación contra la discriminación. Priorizaron que todos los productores de planta pudieran juntarse a comer el bocadillo a costa de aplazar que las trabajadoras fueran reconocidas como tales mediante la obtención de un salario igual:

R: Entonces, en este convenio, tuvimos que llegar a acuerdos sin poder solucionar, nos habíamos metido en una pelea muy grande que era conseguir el cuarto de hora del bocadillo, que entonces salió la ley de las cuarenta horas, nosotros nos metimos con el cuarto de hora del bocadillo y hubo una huelga muy fuerte, una lucha bastante fuerte también y tuvimos que aceptar firmar el convenio una vez que se había conseguido, lo firmamos en septiembre porque no cedíamos en el cuarto de hora de bocadillo y entonces conseguimos el cuarto de hora de bocadillo y no pudimos conseguir más cosas [se retiró de la negociación la igualdad salarial sin convertirse en objeto de disputa de la huelga de 1984] y allí mismo fue cuando firmamos el convenio y dijimos: «Ya no pasa de aquí, es decir, hemos peleado, no hemos conseguido por la lucha tal, pero nosotros no vamos a parar de batallar por ello».

(RmU. Trabajadora especialista, representante de las trabajadoras y los trabajadores. Enunciado en el contexto de la huelga por convenio y el cuarto de hora de bocadillo de 1984.)

El aspecto central en disputa entorno al tiempo es trabajar menos horas ganando más dinero, que se opone a la explotación, condición misma de la existencia del capitalismo. Luego, el tiempo no es un bien por encima del dinero:

R: Luego yo ya empecé que hacíamos huelgas, y yo empecé a coger conciencia de que había que trabajar pero no tantas horas, intentar cobrar más, pero trabajando menos, o sea ya la [...].

([RmJ. Trabajadora especialista, infrafemenina. Enunciado en el contexto de las huelgas por convenio de 1973.)

El tercer objeto en disputa clásico son los convenios. Se trata de huelgas por acordar de forma explícita los términos de la relación entre la empresa y el personal empleado. Estas huelgas expresan la negativa a aceptar condiciones arbitrarias de trabajo,

R: Sí, nosotros teníamos huelga cada año cuando había convenio, con todos los convenios.

(RhA. Trabajador cualificado, masculino, representante de las trabajadoras y los trabajadores. Enunciado en el contexto de las huelgas en general.) 
R: De huelgas de convenios, casi siempre, casi cada año tenemos un mes de huelga.

$(\mathrm{RmJ}$. Trabajadora especialista, infrafemenina. Enunciado en el contexto de las huelgas en general.)

Salario, tiempo, convenio y también condiciones de seguridad e higiene:

R: Porque por medio, desde el setenta y tres había habido incluso huelgas parciales, por el agua, por el calor, aquello que había paros parciales, de dos o tres días que se paraba a una hora o lo que fuera, por el calor, por el agua, que no había agua.

(RmU. Trabajadora especialista, representante de las trabajadoras y los trabajadores. Enunciado en el contexto de las huelgas por mejora de las condiciones de trabajo 1973-1974.)

Finalmente, el orden político es un objeto de disputa especialmente relevante en el contexto de la transición democrática, cuyas contrapartes eran las trabajadoras y los trabajadores de MSA y el gobierno franquista o los golpistas de 1981:

R: Luego, en el setenta y seis hubo una participación en una huelga general que hubo en $S$. por represión, y hubo la huelga en ese mismo año, a finales, que fue por el convenio comarcal del metal, que nosotros no estábamos, teníamos convenio de empresa, pero apoyábamos.

(RmU. Trabajadora especialista, representante de las trabajadoras y los trabajadores. Enunciado en el contexto de las huelgas solidarias de 1976.)

\section{Huelgas y resultados}

Por lo general, las huelgas dan sus resultados. Se logran, grosso modo los objetivos marcados por parte de las personas que participan de una subjetividad antagonista, tras mucho esfuerzo y capacidad de resistencia.

\subsection{Victorias}

Cuando se gana, cuando se alcanzan los objetivos, las trabajadoras y los trabajadores de MSA sienten una gran satisfacción, porque implica frenar las aspiraciones de la empresa, porque supone, por ejemplo, defender a las personas que hubieran podido quedar afectadas por el expediente de empleo de 1997 y porque no había razones aceptables que justificaran ese despido masivo:

R: Sentimos una satisfacción muy grande, en el sentido de que, por medio de la huelga y la presión, habíamos conseguido que el patrono retirara algo que le iba a afectar no sabemos a quién, pero a doscientos sesenta y ocho trabajado- 
res despedidos, y además no veíamos una causa justificá, porque estaban diciendo que está todo muy bien. ¡Coño ¿entonces por qué los echas a la calle?! Y la segunda, pues [...].

(RhA. Trabajador cualificado, masculino, representante de los trabajadores y las trabajadoras. Enunciado en el contexto de las huelgas contra el expediente de rescisión de empleo de 1997.)

La huelga se muestra efectiva, permite lograr objetivos reafirmando la subjetividad antagonista, es un instrumento eficaz para la defensa de los intereses de las trabajadoras y los trabajadores:

R: Se paralizó la huelga y conseguimos unas mejoras importantes.

(RhA. Trabajador cualificado, masculino, representante de las trabajadoras y los trabajadores. Enunciado en el contexto de las huelgas por convenio de 1978.)

R: Total, que estuvimos un mes de huelga y se consiguió que se echara para atrás [el expediente de rescisión de empleo] y no se lo aceptó la administración.

(RhN. Trabajador cualificado, inframasculino. Enunciado en el contexto de las huelgas contra el expediente de rescisión de empleo de 1997.)

Todo ello indica la capacidad de acción, de ofrecer resistencia y, por tanto, que el fundamento de la huelga no es el sujeto, sino el estado de sujeción.

\subsection{Derrotas}

Pero también se pierde, lo que lleva aparejada la disolución de la subjetividad antagonista que se había construido en la propuesta de lucha. Perder significa, por ejemplo, acabar una huelga con despedidos, masivos o disciplinarios, sin lograr la readmisión de los despedidos. Pero la solidaridad llega tan lejos, que los excluidos, los despedidos, permanecen unidos a sus compañeros hasta el momento de perder el empleo:

R: Firmamos, dijimos a la empresa: «bueno, negociemos», estuvimos de huelga todavía y cuando firmamos dijimos a la gente que había que volver al trabajo, que a los cuatro días salían los despedidos, y conseguimos que todo el mundo entrara a trabajar, para ellos fue muy duro, pero se consiguió entrar a trabajar.

(RmU. Trabajadora especialista, representante de las trabajadoras y los trabajadores. Enunciado en el contexto de las huelgas contra el expediente de rescisión de empleo de 1997.)

R: Por eso se saldó la del setenta y cuatro, que fue una huelga que no fue victoriosa, con dieciséis despidos. 
(RmU. Trabajadora especialista, representante de las trabajadoras y los trabajadores. Enunciado en el contexto de las huelgas por convenio de 1974.)

Perder, es que la empresa no tenga huelgas. Es decir, la empresa gana la paz social como marco más ágil para continuar la explotación capitalista: si quieres conservar tu empleo, no puedes defender tus condiciones de trabajo:

R: Y yo les digo a ellos [a los representantes de los trabajadores] digo: «Oye, no nos compliquemos la vida». Podemos salir beneficiosos, yo no quiero ningún follón, tenemos que tener capacidad las partes para ponernos de acuerdo y firmar un convenio que nos dé vía para cuatro años, porque, al final, el trabajo llega $[\ldots]$.

(RhK. Directivo, masculino. Enunciado en el contexto de las huelgas en general)

\subsection{Los logros}

Los logros que más destacan las personas entrevistadas, y que ya han aparecido señalados en los apartados anteriores, giran en torno al salario, el tiempo y el empleo. En cuanto al salario, las mujeres que han expresado la subjetividad nosotras, las mujeres trabajadoras destacan la victoria contra la discriminación salarial de las mujeres de producción directa de 1989. En cuanto al tiempo, logran aumentar los intervalos de descanso, consiguiendo el cuarto de hora para el bocadillo, en 1984. Pero no es propiamente una huelga por el tiempo, como ya hemos comentado, dado que no se plantea ese rebaje de horas anuales (54 en total) como un tiempo ganado para no estar en la empresa. Ese tiempo sigue siendo tiempo en la empresa. Lo que está en juego es lograr espacios para las relaciones entre todas las trabajadoras y los trabajadores. El cuarto de hora de bocadillo es un espacio de encuentro y de establecimiento y sostenimiento de vínculos entre las personas que trabajan en la planta de producción. En esos momentos, la gente habla, comenta lo que ocurre en la empresa y en casa, se reconocen a los unos a los otros. Se trata de un tiempo que facilita el sostenimiento de una subjetividad solidaria. Así mismo, las luchas por el tiempo comportan imponer una leve tendencia decreciente en el número de días y horas de trabajo efectivo anual. Dieciocho años de lucha para lograr un descenso algo superior al 6\% en el número de horas trabajadas. En la tabla 6 recogemos el crecimiento de días y horas que, para el período del que se dispone de datos, prácticamente ha sido siempre negativo.

En cuanto al empleo, el logro más importante ha sido frenar el impacto del despido masivo que conllevó el expediente de rescisión de empleo de 1997, al salvar más de cien puestos de trabajo (tabla 7).

Finalmente, habría un resultado genérico de los procesos de huelga que se han desarrollo a lo largo de la historia de las relaciones laborales de las trabajadoras y los trabajadores de MSA con la dirección de la empresa. La huelga 
Tabla 6. Crecimiento de días y horas efectivas de trabajo pactadas con la empresa (1983-2001)

\begin{tabular}{lccccc}
\hline $\begin{array}{l}\text { Año } \\
\text { efectivos año }\end{array}$ & $\begin{array}{l}\text { Total dís } \\
\text { efectivas año }\end{array}$ & Año & $\begin{array}{l}\text { Total días } \\
\text { efectivos año }\end{array}$ & $\begin{array}{l}\text { Total horas } \\
\text { efectivas año }\end{array}$ \\
\hline 1983 & 228 & 1.861 & 1994 & 226 & 1.750 \\
\hline 1984 & 228 & 1.833 & 1995 & 225 & 1.750 \\
\hline 1985 & 228 & 1.770 & 1996 & 227 & 1.750 \\
\hline 1988 & 227 & 1.770 & 1997 & 227 & 1.750 \\
\hline 1989 & 226 & 1.770 & 1998 & 226 & 1.750 \\
\hline 1990 & 228 & 1.770 & 1999 & 223 & 1.754 \\
\hline 1991 & 227 & $* 1.770$ & 2000 & 220 & 1.742 \\
\hline 1992 & 226 & 1.750 & 2001 & 220 & 1.742 \\
\hline 1993 & 228 & 1.750 & & & \\
\hline
\end{tabular}

Tasa de variación interanual Total días efectivos año Total horas efectivas año 1983-2001 $-3,5 \%$ $-6,4 \%$

* = Estimado.

Fuente: Material de archivo. Elaboración propia.

Tabla 7. Diferencia entre el primer expediente de rescisión de empleo y el segundo en número de despidos

\begin{tabular}{|c|c|c|c|c|c|}
\hline & \multicolumn{2}{|c|}{$\begin{array}{l}\text { Primera presentación } \\
\text { del expediente de rescisión } \\
\text { de empleo (abril de 1997). } \\
\text { Retirado }\end{array}$} & \multicolumn{2}{|c|}{$\begin{array}{l}\text { Segunda presentación } \\
\text { del expediente de rescisión } \\
\text { de empleo (octubre de } \\
\text { 1997). Aprobado }\end{array}$} & \multirow[t]{2}{*}{ Diferencia } \\
\hline & $N$ & $\begin{array}{l}\% \text { sobre } \\
\text { la plantilla previa }\end{array}$ & $N$ & $\begin{array}{l}\% \text { sobre } \\
\text { la plantilla previa }\end{array}$ & \\
\hline $\begin{array}{l}\text { No de trabajadoras } \\
\text { y trabajadores despedidos }\end{array}$ & 268 & $63,4 \%$ & 159 & $37,6 \%$ & $-26 \%$ \\
\hline $\begin{array}{l}\text { No de trabajadoras y trabajadores } \\
\text { que mantienen el empleo }\end{array}$ & 155 & $36,6 \%$ & 264 & $62,4 \%$ & $26 \%$ \\
\hline Plantilla previa al expediente: & 423 & & & & \\
\hline
\end{tabular}

Fuente: Material de archivo. Elaboración propia.

como amenaza, como implícito en cualquier negociación. Y su reverso también está. El implícito del cierre de la empresa, del despido masivo si hay huelgas. Se dibuja, así, una cotidianeidad en la relación en la empresa, entre las partes, compleja. En la situación actual, la empresa MSA está presidida por la paz social, la tranquilidad, se logran determinados acuerdos a medio plazo y las contrapartes están interesadas en conseguir esos acuerdos. Sin embargo, ese punto de unión, lejos de ser una sintonía, es simplemente una forma de des- 
plazar a un plano menos evidente el conflicto implícito y la lucha que caracteriza y da forma a las partes: la huelga, y su reverso patronal, el cierre. Un implícito siempre presente.

\section{Conclusiones}

Si entendemos que la subjetividad se elabora de una forma discursiva y fragmentaria, la noción de intereses de clase requiere ser revisada. Como decíamos más arriba, el momento innovador ante la dinámica cotidiana pasa, más que por el yo, por el nosotros. Si aceptamos que nos vamos produciendo como sujetos en las relaciones que establecemos con los demás, es razonable pensar que también a través de las relaciones con los demás, nos innovamos, puesto que planteamos alternativas a nuestra manera de vivir, sean éstas conservadoras o transformadoras. Pues bien, la construcción de los intereses pasa también por el momento nosotros. Según como construyamos ese nosotros, podremos establecer distintos intereses. En el caso de los de clase, se refieren a nuestra participación en las relaciones de producción. La elaboración colectiva de los intereses en términos de un nosotros clase implica priorizar, dado que los intereses sometidos a elaboración como nosotros clase se refieren únicamente a las relaciones de producción, mientras que no son los únicos que manejamos en nuestra vida como sujetos individuales. La prioridad de las luchas de clases para transformar las relaciones de producción, para mejorar salarios y horarios sobre la lucha por abolir la dictadura heterosexual, por poner un ejemplo, resulta de esa elaboración colectiva. El implícito de esta argumentación es que la elaboración de los intereses es un proceso reflexivo. Si no, hablaríamos de deseos, de preferencias no pensadas. Evidentemente, éstas influyen sobre nuestros intereses.

Las prioridades, las estrategias, los objetivos, se muestran abiertos, aunque su elaboración está situada en las relaciones de producción en las que participamos y, en general, en el conjunto de relaciones sociales de las que formamos parte. Que la clase trabajadora tenga un interés objetivo en el socialismo, no deja de ser un producto elaborado en un contexto histórico por un determinado nosotros que se ha ido constituyendo históricamente hasta hoy en día. Podría ser, como históricamente fue, una transformación socialista libertaria, socialista feminista libertaria, que persiguiera no sólo la supresión de las relaciones de producción capitalista y las clases que ellas generan, sino también las patriarcales. Todos esos intereses se elaboran en las interacciones sociales. Y esa elaboración no es una circunstancia para siempre. Necesita de la constante reelaboración en las relaciones que sostenemos. Evidentemente, este planteamiento tiene consecuencias. Ya no hablamos de falsa conciencia y, por lo tanto, de falsos intereses. En este sentido, «[...] el individuo se encuentra ante una serie de elecciones, y unas de ellas puede ser la de hacerse obrero y otra la de decidir cooperar con otros obreros. Pero tiene posibilidades de elección, y hemos de analizar toda esa estructura de posibilidades como dadas a individuos, no a obreros. Porque es verdad que hay situaciones en las que pueden decidir hacerse obreros y cooperar con los capitalistas en contra de otros obreros y la opti- 
milidad de esta estrategia puede ser incomprensible si truncamos el juego de elecciones viendo a los individuos como obreros prefabricados. Es posible que blancos y negros no cooperen como obreros, porque para los capitalistas es lógico dividir y vencer, pero además no colaboran porque son blancos y negros, no sólo obreros» (Przeworski, 1988 [1985]: 116).

Así mismo, no siempre tienen que sostenerse los mismos intereses a lo largo de nuestra vida. Hablaríamos de momentos de cambio, de ruptura de esos nosotros. Más que hablar de tomar conciencia de los verdaderos intereses, se trata de elaborar intereses que, apelando a la supresión de la explotación, a la justicia, al menor sufrimiento, a la felicidad, permiten acercarse a esos ideales. Un proceder que es idéntico al que inspira la elaboración de intereses de los propios capitalistas que implica apelar a principios éticos, políticos y morales. En este sentido, tiene tanto de utópico una transformación social igualitaria y libertaria como la capitalista, con la diferencia que, quienes ahora están dirigiendo el mundo hacia una utopía son precisamente los revolucionarios capitalistas. La elaboración de los intereses, así sea a través de organizaciones colectivas o cuando estamos en casa, o en el puesto de trabajo, implica siempre operaciones políticas que se conectan con nuestros deseos que conocemos y que desconocemos. Y esto porque somos seres morales y éticos que nos producimos en las relaciones con los demás. En este sentido, negar la elaboración abierta de intereses, desde las relaciones de producción que nos constriñen pero que podemos trascender, no deja de ser fruto de la elaboración de los intereses de algún ellos.

\section{Referencias bibliográficas}

Babiano, J. (1995). Emigrantes, cronómetros y huelgas. Madrid: Siglo XXI. Historia. BREDEMEIER, H. C. (1988) (1978). "La teoría del intercambio». En: BOTTOMORE, T.; NisbeT, R. (comps.). Historia del análisis sociológico. Buenos Aires: Amorrortu, p. $477-521$.

CARCHEDI, G. (1975). "On the Economic Identification of the New Middle Class». Economy and Society, vol. 4, núm. 1.

ElSTER, J. (2001) (1999). Sobre las pasiones. Barcelona: Paidós. Transiciones, 32.

- (1997) (1989). El cemento de la sociedad. Barcelona: Gedisa. Sociología. Serie CLA.DE.MA.

- (1995) (1979). Ulises y las sirenas. México DF: Fondo de Cultura Económica. Breviarios, 510 .

- (1988) (1983). Uvas amargas. Barcelona: Península. Península Ideas, 4.

Habermas, J. (1987) (1981). Teoría de la acción comunicativa, vol. I y II. Madrid: Taurus. Ensayistas, 278.

HARTMANN, H. (1980) (1976). «Capitalismo, patriarcado y segregación de los empleos por sexo». En: EINSENSTEIN, Z. (comp.). Capitalismo patriarcal y feminismo socialista. Madrid: Siglo XXI, p. 186-221.

IZQUIERDO, M. J. (dir.) (1998a). Aguantando el tipo. La lucha contra la discriminación salarial. Barcelona: Diputació de Barcelona.

- (1998b). El malestar en la desigualdad. Madrid: Cátedra. Feminismos, 48. 
LAClAU, E. (1998) (1985). «Desconstrucción, pragmatismo, hegemonía». En: MoUfFE, CH. Desconstrucción y pragmatismo. Buenos Aires: Paidós, p. 97-136.

LAClaU, E.; MOUfFe, C. (1987) (1985). Hegemonía y estrategia socialista: Hacia una radicalización de la democracia. Madrid: Siglo XXI. Sociología y Política.

Marglin, S. A. (1977). "Orígenes y funciones de la parcelación de las tareas. ¿Para qué sirven los patronos?». En: GORZ, A. Crítica de la división del trabajo. Barcelona: Laia, p. 45-96.

Miliband, R. (1990) (1987). «Análisis de clases». En: Giddens, A.; Turner, J. y otros. La teoría social hoy. Madrid: Alianza, p. 418-444.

- (1985). El Estado en la sociedad capitalista. Madrid: Siglo XXI.

Mingione, E. (1993) (1991). Las sociedades fragmentadas. Madrid: Ministerio de Trabajo y Seguridad Social. Economia y Sociología del Trabajo, 67.

MorA, E. (2005). «Patriarcado, capitalismo y clases sociales». En: Giró, J. (ed.). El género quebrantado. Madrid: Catarata.

- (2003). "La construcción de subjetividades fragmentarias de clase. Un ejemplo». Athenea Digital, 3. Disponible en <http://antalya.uab.es/athenea/num3/XXXX.pdf>.

- (2002). Las clases sociales como forma de interacción social: Una estrategia de aproximación. Tesis doctoral. Barcelona: Universitat Autònoma de Barcelona.

Mouffe, C. (comp.) (1998) (1996). Desconstrucción y pragmatismo. Buenos Aires: Paidós.

- (1993) (1992). «Feminismo, ciudadanía y política democrática radical». Debate Feminista, 7, p. 3-58.

POLANYI, K. (1989). La gran transformación. Madrid: La Piqueta. Genealogía del Poder, 17. Poulantzas, N. (1978) (1969). Poder político y clases sociales en el estado capitalista. México: Siglo XXI.

- (1977) (1974). Las clases sociales en el capitalismo actual. México: Siglo XXI.

PRZEWORSKI, A. (1995) [1991]. Capitalismo y socialdemocracia. Madrid: Alianza. Alianza Universidad.

- (1988) (1985). Democracia y mercado. Cambridge: Cambridge University Press. - (1987) (1985). "Marxismo y elección racional». Zona Abierta, 45, p. 97-136. SCASE, R. (1992). Class. Buckingham: Open University Press.

Thompson, E. P. (1989) (1963). La formación de la clase obrera en Inglaterra, vol. 1 y 2. Barcelona: Crítica. Crítica Historia del Mundo Moderno.

- (1984). Tradición, revuelta y conciencia de clase. Barcelona: Crítica. Crítica Historia.

WRIGHT, E. O. (1995) (1989). "Reflexionando, una vez más, sobre el concepto de estructura de clases». En: CARABAÑA, J.; Francisco, A. de (comps.). Teorías contemporáneas de las clases sociales. Madrid: Pablo Iglesias, p. 17-125.

- (1995). "Análisis de clase». En: CARABAÑA, J. Desigualdad y clases sociales: Un seminario en torno a E. O. Wright. Madrid: Visor y Fundación Argentaria, p. 21-53.

- (1994) (1985). Clases. Madrid: Siglo XXI. Sociología y Política.

- (1983) (1978). Clase, crisis y Estado. Madrid: Siglo XXI. 


\section{Anexo}

El perfil remite a la posición en la empresa (laboral y sindical) y en el ámbito familiar. El conjunto de perfiles empleados es el que indicamos a continuación:

\section{Listado de perfiles}

\begin{tabular}{lll}
\hline Trabajadora especialista & Infrafemenina & \\
Trabajadora especialista & Neutro & Representante de las trabajadoras y los trabajadores \\
Trabajadora especialista & - & \\
Trabajador especialista & Inframasculino & \\
Trabajador especialista & Inframasculino & Representante de las trabajadoras y los trabajadores \\
Trabajadora cualificada & Infrafemenina & \\
Trabajador cualificado & Masculino & Representante de las trabajadoras y los trabajadores \\
Trabajador cualificado & Inframasculino & \\
Team leader & Infrafemenina & \\
Team leader & Masculino & \\
Team leader & Inframasculino & \\
Administrativo & Inframasculino & \\
Administrativo & Neutro \\
Técnico & Masculino \\
Directivo & Masculino \\
Ama de casa (en exclusiva) & Femenina
\end{tabular}

Indicamos los perfiles de las personas entrevistadas a las cuales efectivamente hemos podido acceder.

En cuanto a la terminología usada, sólo comentar la que remite al género. Para referirnos a la pluralidad de situaciones que se desprenden de la definición simultánea de un perfil en el ámbito capitalista y patriarcal, hemos querido simplificar la terminología apoyándonos, con algunas modificaciones y recortes, en la tipología de género de Izquierdo (1998b: 44). Así, en lugar de decir, por ejemplo, «trabajador cualificado ganador de pan casado con un ama de casa en exclusiva», decimos "trabajador cualificado masculino». A continuación, indicamos a qué corresponde cada término usado para la identificación de género, desde el punto de vista del par conceptual «ganador de pan» y «ama de casa»:

- Femenino: personas cuya relación con el cabeza de familia es la de esposa o esposo, que se definen como ama de casa (en exclusiva) cuando se les pregunta sobre su ocupación. Ama de casa en exclusiva casada con un ganador de pan. - Infrafemenino: personas cuya relación con el cabeza de familia es la de esposa o esposo, que se definen como activas (ocupadas o paradas) o jubiladas 
y como ama de casa cuando se les pregunta sobre su ocupación y que consideran que sus ingresos son complementarios. El término infrafemenino no es empleado por Izquierdo (habla de superfemenino), y se lo debo a Francisco José León. Trabajadora y ama de casa casada con un ganador de pan.

- Masculino: personas que ocupan el lugar de cabeza de familia, que viven en hogares de más de un miembro, que se definen como activas (ocupadas o paradas) o jubiladas y que consideran que sus ingresos son familiares. Ganador de pan casado con una ama de casa en exclusiva.

- Inframasculino: personas que ocupan el lugar de cabeza de familia, que viven en hogares de más de una persona, que se definen como activas (ocupadas o paradas) o jubiladas, que consideran que sus ingresos son familiares y que son esposo o esposa de personas de género infrafemenino. El término inframasculino no es empleado por Izquierdo (habla de supermasculino), y se lo debo a Francisco José León. Ganador de pan casado con trabajadora y ama de casa.

- Neutro: personas que viven solas y que se definen como activas (ocupadas o paradas) cuando se les pregunta sobre su ocupación.

Finalmente, para los casos que no corresponden a esta tipología, no indicamos el género. 